\title{
ASPECT RATIO FACTOR FOR FINITE ELEMENT METHOD ANALYSIS OF AXIALLY SYMMETRIC CYLINDRICAL SHELL WALLS
}

\author{
Gebrail BEKDAŞ, Namık Kemal ÖZTORUN \\ Department of Civil Engineering, Istanbul University, 34320 Avclar, Istanbul, Turkey
}

Received 10 October 2014; accepted 28 November 2014

\begin{abstract}
Finite Element Method (FEM) is one of the most commonly used numerical analysis method for the structural analysis. The axially symmetric cylindrical shell walls analysis can be made by using FEM or similarity of beams on elastic foundation. The Superposition Method (SPM) is a method developed for the analysis of beams and can be employed in the analysis of cylindrical shell walls.

In the analyses using FEM, there are some assumptions and boundaries for preparing mathematical models. One of these boundaries for shell walls is aspect ratio. In this study, it is investigated, the aspect ratio factor for FEM analysis of axially symmetric cylindrical shell walls. For that reason the FEM analysis results are compared with the Superposition Method (SPM). In order to obtain exact solution of cylindrical shell walls, the effects of loadings is calculated and defined to the computer program, which is developed for SPM analysis by using Visual Basic programming language. According to analysis results, aspect ratio has a significantly effect on analysis results. Also, it is occurred minor difference in the FEM analysis results even if in case of obeying the rules.
\end{abstract}

Keywords: aspect ratio factor, axially symmetric cylindrical shell walls, beams on elastic foundation, Superposition method, Finite element method.

\section{Introduction}

The differential equation of axially symmetric cylindrical wall and beams on elastic foundations are similar (Timoshenko, Woinowsky-Krieger 1984). By using this similarity, it can be made analysis of cylindrical shell walls.

The elastic soil model, which is used beams on elastic foundation, is first introduced by Winkler (1867). In the Winkler model, soil is defined as infinite number of independent springs. Also, there is a ratio between contact pressure and settlement of point named modulus of foundation. Winkler used his soil model in railway stress analysis by defining rails as beams (Wang et al. 2005; Karaşin, Gülkan 2008). By using Winkler's assumption, many studies have made on railway stress analysis (Kerr 1976).
Beside the railway analysis, the elastic foundation theory has been employed in solving various engineering problems, including retaining walls, strip- continuous footing and axially symmetric cylindrical shell walls. Thus, many researchers from different department of engineering science are worked on this subject.

Deflection line equation of beams on elastic foundation is including four constant of integration. Since, these constant are changing in each discontinuous loading, determining of them is the main difficulty encountered during analysis. It is developed various alternative methods that can be found in several books to overcome this difficulty (Selvadurai 1979; Jones 1997; Melerski 2000). The initial conditions method developed by Umansky (1933) and the superposition method developed by Hetenyi $(1936,1946)$ are the most commonly employed methods.

Corresponding author:

G. Bekdaş E-mail: bekdas@istanbul.edu.tr 
Levinton (1947) method consists in representing the pressure of the elastic foundation as a series of redundant reactions. Penzien (1960) have used an iterative procedure, which is similar to $\mathrm{H}$. Cross (1930), for obtaining discontinuity stress in beams and cylinder. The method by Popov (1951) resembles moment-area procedure for solving beams. To calculate the influence coefficient for beams, a solution in the form of a series of characteristic function is presented by Iyengar and Anantharamu $(1963,1965)$. Miranda and Nair (1966) is used the initial condition method for solving differential equation of beams of finite length. The finite difference method has been applied by Beaufait (1977) to solve differential equation of a beam- column structure on elastic foundation. Ting (1982) improved the special functions, which is given in initial condition method, in order to contact the analysis for different boundary condition. Eisenberger and Yankelevsky $(1984,1986)$ are formulated an exact stiffness matrix of a beam and beam-column problems on elastic foundation.

By using similarity of beams on elastic foundation the analysis of axially symmetric cylindrical shell walls has been introduced in several books, written about shell structures (Billington 1965; Ghali 1979; Calladine 1983; Kelkar, Sewell 1987; Ventsel, Krauthammer 2001). In addition, it has been developed some methods about cylindrical shell walls analysis.

Öztorun and Utku (2002) are presented a method based on classical shell theory for the analysis of cylindrical water tanks under axisymmetric and post tensioning loading. In another study five moment equations is employed by Öztorun et al. (1996) for the analysis. An alternative method for the analysis of short cylindrical shell walls is presented by Bekdaş (2011). Also, Bekdaş developed a computer program based on this method. Recent studies on cylindrical shell walls also cover optimization, experimental and numerical analyses (Barakat, Altoubat 2009; Ansary et al. 2011; Shariati et al. 2012; Lakshmia, Rao 2012; Yu, Ma 2012; Yas et al. 2011; Aghajari et al. 2011; Kala 2007).

Also, Finite Element Method (FEM), which is a numerical analysis technique, can be used for the analysis of cylindrical shell walls. Although FEM is a powerful numerical analyses technique, it makes some assumptions and has some boundaries for preparing mathematical models. It can be occurred big mistakes in the analysis results in case of not obey these rules. Aspect ratio is one of these boundaries of FEM.
In the study, it is investigated the SPM and FEM for analysis of axially symmetrical cylindrical shell walls. It is mentioned about the assumptions and the principle of methods, which can significantly affect the analysis results. It is aimed to show error rates of FEM analysis results, when it is not used properly. Computer programs are developed in Visual Basic, based on SPM. In order to obtain exact solution of cylindrical shell walls, the effects of loadings is calculated and defined to the program.

\section{Methodology}

The general expressions for axisymmetric deformation in circular cylindrical shell walls, when the thickness of the wall is constant, can be written as:

$$
\begin{aligned}
& D \frac{d^{4} w}{d x^{4}}+\frac{E h}{r^{2}}=q ; \\
& D=\frac{E h^{3}}{12\left(1-v^{2}\right)},
\end{aligned}
$$

where $D$ is the flexural rigidity of the wall (Eq. (2)), w is inward radial deflection of the wall midsurface, $r$ is radius of the wall, $q$ is the radial pressure loading and $h$ is the thickness of the cylindrical shell wall. In the Eq. (1), by using the term:

$$
\beta^{4}=\frac{E h}{4 r^{2} D}=\frac{3\left(1-v^{2}\right)}{r^{2} h^{2}},
$$

differential equation becomes:

$$
\frac{d^{4} w}{d x^{4}}+4 \beta^{4} w=\frac{q}{D}
$$

This equation is similar to the beams on elastic foundation (Timoshenko, Woinowsky-Krieger 1984) and general solution of this equation is:

$$
\begin{aligned}
& w=e^{\beta x}\left(C_{1} \cos \beta x+C_{2} \sin \beta x\right)+ \\
& e^{-\beta x}\left(C_{3} \cos \beta x+C_{4} \sin \beta x\right)+f(x),
\end{aligned}
$$

where $f(x)$ is a particular solution of equation and $C_{1}$, $C_{2}, C_{3}$ and $C_{4}$ are the integration constants determining from boundary conditions of the cylinder shell wall. The general expression for the deflection line of beams on elastic foundation is:

$$
\begin{aligned}
& w=e^{\lambda x}\left(C_{1} \cos \lambda x+C_{2} \sin \lambda x\right)+ \\
& e^{-\lambda x}\left(C_{3} \cos \lambda x+C_{4} \sin \lambda x\right)+f(x) .
\end{aligned}
$$

In the equation $\lambda$ is an inserting term that is used in simplifying the differential equation and it can be written as:

$$
\lambda=\sqrt[4]{\frac{k}{4 E I}},
$$


where $k, E I$ is modulus of the foundation and flexural rigidity, respectively. When the equations of walls (Eq. (5)) and beams (Eq. (6)) are examined, it is seen that the main difference between these equations is $\beta$ parameter in the shell walls and $\lambda$ in the beams.

In the superposition method integration constants are being determined by the help of infinite long beam. Thus, we decrease the mathematical operation during the analysis. This process provides an advantage to superposition method comparing to the others. Also, this procedure is making application easier to particular problems.

An infinite beam subjected to concentrated load and moment can be seen in Figure 1. It is obvious that, in an infinite distance from the application of the load displacements, moment and shearing forces values are decreasing and approach to zero. By using this behavior of infinite beam, the deflection line, which is given in Eq. (6), and $\theta, M$ and $Q$ expressions, can be written as:

$$
\begin{gathered}
w=\frac{P \lambda}{2 k} A_{\lambda x} ; \\
\theta=-\frac{P \lambda^{2}}{k} B_{\lambda x} ; \\
M=\frac{P}{4 \lambda} C_{\lambda x} ; \\
Q=-\frac{P}{2} D_{\lambda x} .
\end{gathered}
$$

With similar approach, expressions for infinite beam subjected to concentrated moment can be obtained (Fig. 1):

$$
w=\frac{M_{0} \lambda^{2}}{k} B_{\lambda x}
$$

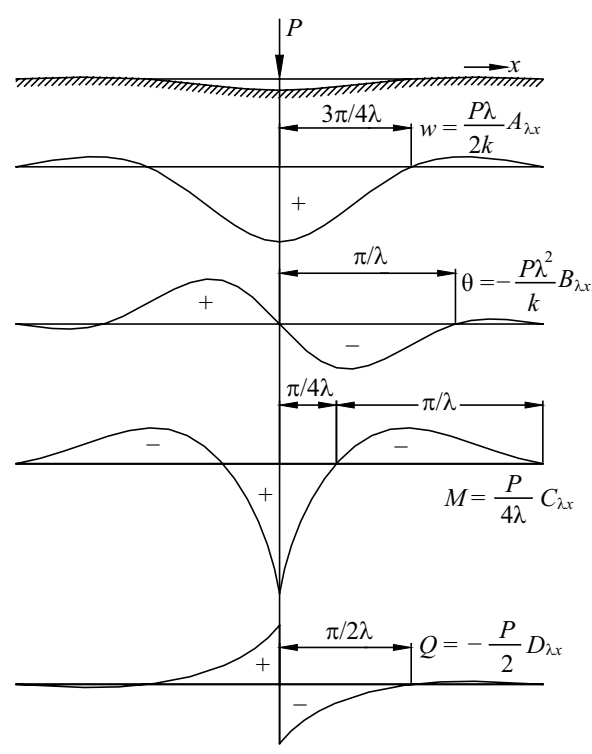

$$
\begin{gathered}
\theta=\frac{M_{0} \lambda^{3}}{k} C_{\lambda x} ; \\
M=\frac{M_{0}}{2} D_{\lambda x} ; \\
Q=-\frac{M_{0} \lambda}{2} A_{\lambda x},
\end{gathered}
$$

where the $A_{\lambda \mathrm{x}}, B_{\lambda \mathrm{x}}, C_{\lambda \mathrm{x}}$ and $D_{\lambda x}$ functions are:

$$
\left.\begin{array}{l}
A_{\lambda x}=e^{-\lambda x}(\cos \lambda x+\sin \lambda x) \\
B_{\lambda x}=e^{-\lambda x} \sin \lambda x \\
C_{\lambda x}=e^{-\lambda x}(\cos \lambda x-\sin \lambda x) \\
D_{\lambda x}=e^{-\lambda x} \cos \lambda x
\end{array}\right\} .
$$

Decreasing amplitude rapidly is the most significant feature of these functions. The value of any four functions for $\lambda x / \pi>1$ is under 0.05 . This means, a beam length $l=2 \pi / \lambda$ subjected a concentrated force or moment at the middle point shows approximately the same behavior as the infinitely long beam. By using this behavior, the beams can be categorized as $\lambda l>\pi$ is long beams and $\lambda l>\pi$ is short beams.

As it was mentioned before, the main problem encountered in analyzing beams on elastic foundation is to determine the integration constants. Since there is only two constant of integration that must be determined, in the long beam it is easier to analyses them comparing to short beams.

The superposition method can be explained briefly in two steps. In the first step, beam is analyzed as infinite long beam and obtained displacement and forces at the end of beam. The second step, we find the loading combination at the end of beam, which satis-

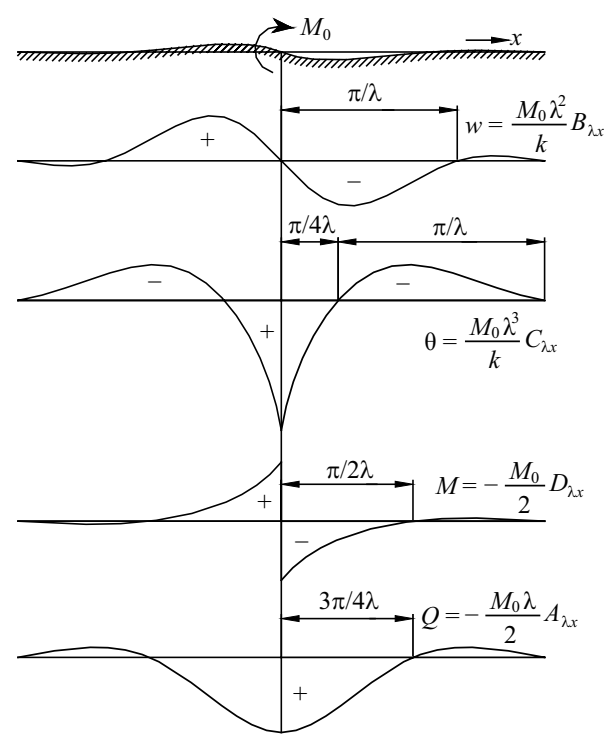

Fig. 1. Infinite beam subjected to concentrated load (left) and moment (right) 
fies boundary condition. By superposing both effects, we obtain a solution for beam.

As an example, a beam subjected to the concentrated and distributed loads is given in Figure 2a. Beam is solved as infinite beam and obtained forces at the end of it (Fig. 2b). And then, we obtain the load combination which satisfied the end condition of beam (Fig. 2c). Since both end of beam is free, in order to obtain analyses results of beam in Figure 2a, we have to make the moments and shearing forces zero, which is occurred at $A$ and $B$ points in the infinite beam (Fig. 2b), by applying the end conditioning forces $P_{0 A}$, $M_{0 A}, P_{0 B}$ and $M_{0 B}$ at those points (Fig. 2c). Thus, the behavior of the infinitely long beam in Figure $2 c$ will be the same as the beam in Figure 2a.
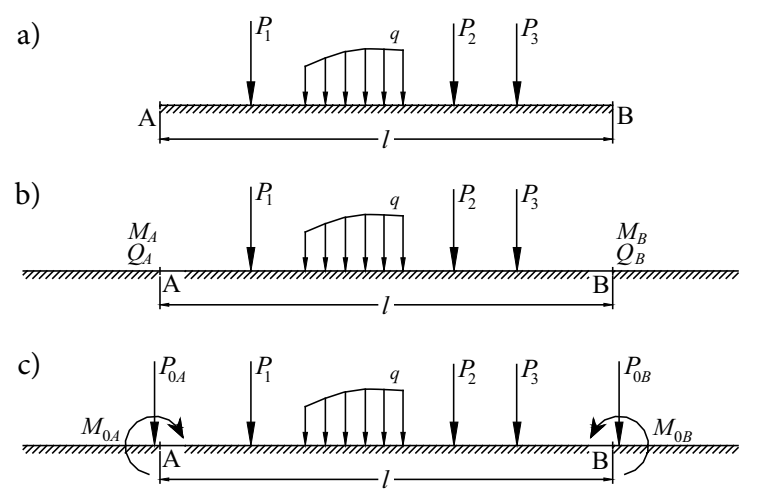

Fig. 2. Infinite beam subjected to various loads

We can determine the end conditioning forces by using the equations that is written four conditions at two ends (Eqs (17)-(20)):

$$
\begin{gathered}
M_{A}+\frac{P_{0 A}}{4 \lambda}+\frac{P_{0 B}}{4 \lambda} C_{\lambda l}+\frac{M_{0 A}}{2}+\frac{M_{0 B}}{2} D_{\lambda l}=0 \\
Q_{A}-\frac{P_{0 A}}{2}+\frac{P_{0 B}}{2} D_{\lambda l}-\frac{\lambda M_{0 A}}{2}+\frac{\lambda M_{0 B}}{2} A_{\lambda l}=0 \\
M_{B}+\frac{P_{0 A}}{4 \lambda} C_{\lambda l}+\frac{P_{0 B}}{4 \lambda}+\frac{M_{0 A}}{2} D_{\lambda l}+\frac{M_{0 B}}{2}=0 \\
Q_{B}-\frac{P_{0 A}}{2} D_{\lambda l}+\frac{P_{0 B}}{2}-\frac{\lambda M_{0 A}}{2} A_{\lambda l}-\frac{\lambda M_{0 B}}{2}=0
\end{gathered}
$$

where $A_{\lambda 1}, B_{\lambda l}, C_{\lambda 1}$ and $D_{\lambda 1}$ are the value of these function at $x=l$. The Eqs (17)-(20) is obtained for beams with free end. If there is another boundary condition at the end of beam, the equation must be formed again to provide it.

\section{Numerical examples}

In this section, there are selected two axially symmetrical cylindrical shell wall models and they are analy- zed with superposition method and FEM. Algorithms are developed in order to make the analyses with SPM, and also computer programs based on these algorithms are developed by using Visual Basic programming language.

The linear FEM analysis is conducted by using SAP2000 program. Cylindrical shell wall model is prepared by using axisymmetric properties, in order to reduce analysis and FEM model preparing time (Fig. 3). In the both examples, the supports conditions is fixed at the bottom and free at the top of the wall.

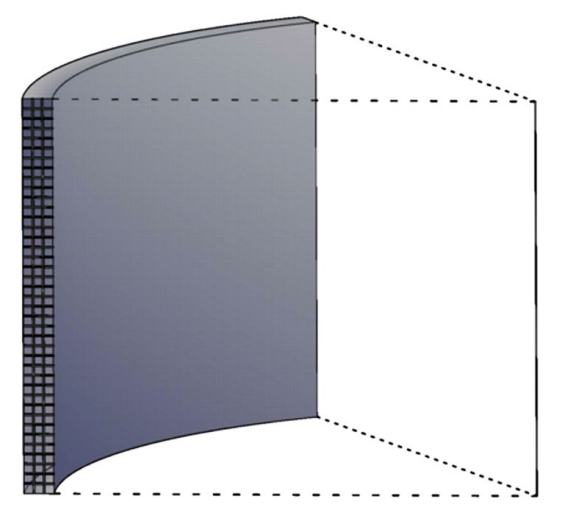

Fig. 3. An axisymmetric model of cylindrical shell wall

Although the required number of element is decreased in the axisymmetric model comparing to three dimensional models, when thickness of structural component is thin, required member increases because of avoiding high element aspect ratios.

\subsection{Example 1}

The radius, thickness, height, elasticity modulus and Poisson's ratio of the first model is $18.25 \mathrm{~m}, 0.30 \mathrm{~m}$, $4.0 \mathrm{~m}, 20601000 \mathrm{kN} / \mathrm{m}^{2}$ and 0.15 , respectively. It is selected liquid load up to height of wall with specific weigh is $9.81 \mathrm{kN} / \mathrm{m}^{3}$, as loading.

In order to investigate effect of changing aspect ratio on analyze results, seven different FEM model are prepared (Fig. 4).

In models, the thickness of the shell wall is divided into three equal pieces. Thus, thickness of each element becomes $0.1 \mathrm{~m}$ and aspect ratios are obtained by changing height of the members. The member dimensions and aspect ratios, which are used in models, can be seen in the Table 1 .

Longitudinal moment of FEM models can be seen in the Figure 5. Also, in the figure the superposition method (SPM) analyses result is given for comparing 


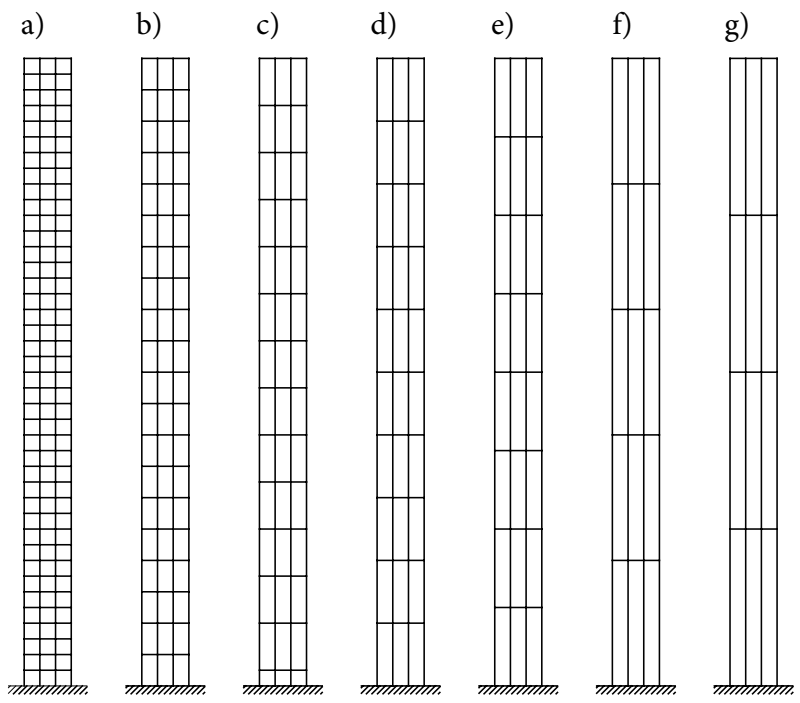

Fig. 4. FEM models with different aspect ratios (Ex.1)

Table 1. Member dimensions and aspect ratios

\begin{tabular}{|c|c|c|}
\hline Model & $\begin{array}{c}\text { Finite element member } \\
\text { height/thickness }(\mathrm{m} / \mathrm{m})\end{array}$ & Aspect Ratio \\
\hline $\mathrm{a}$ & $0.1 / 0.1$ & 1 \\
\hline $\mathrm{b}$ & $0.2 / 0.1$ & 2 \\
\hline $\mathrm{c}$ & $0.3 / 0.1$ & 3 \\
\hline $\mathrm{d}$ & $0.4 / 0.1$ & 4 \\
\hline $\mathrm{e}$ & $0.5 / 0.1$ & 5 \\
\hline $\mathrm{f}$ & $0.8 / 0.1$ & 8 \\
\hline $\mathrm{g}$ & $1.0 / 0.1$ & 10 \\
\hline
\end{tabular}

the FEM results. As seen in the figure, the longitudinal moment differences between SPM and FEM are reduced by decreasing aspect ratio of models.

In the Table 2, the maximum moment values obtained from analyses FEM models and SPM are given. The fixed support moment differences between FEM and SPM is obtained $11.14 \%$ for model $\mathrm{d}$ (aspect ratio

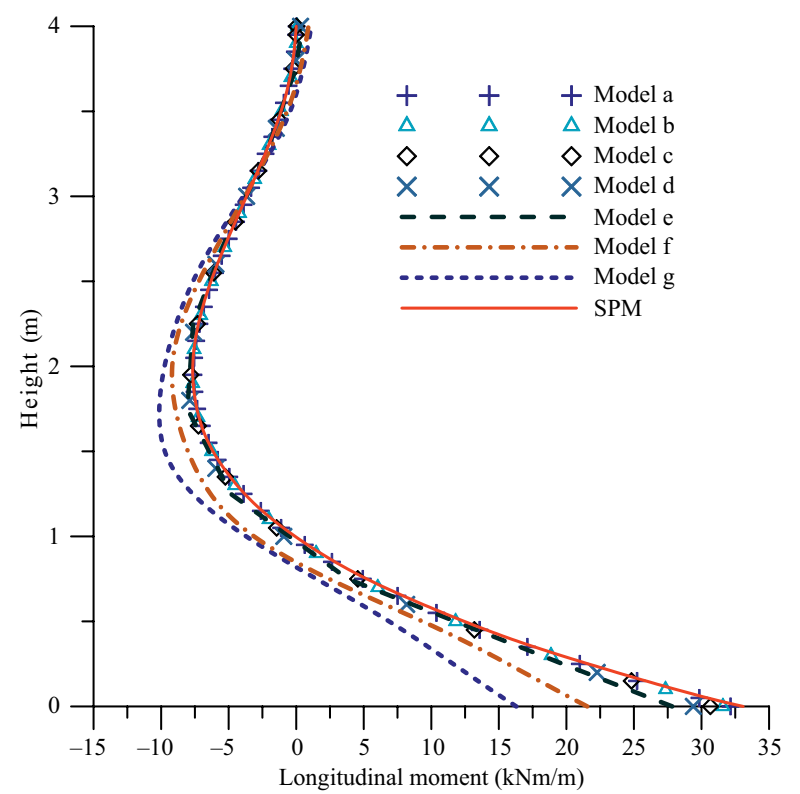

Fig. 5. Longitudinal moments for FEM models and SPM (Ex.1)

is 4 ) and $50.76 \%$ for model $g$ (aspect ratio is 10 ). The longitudinal moment differences is found for model e (aspect ratio is 5) and for model $\mathrm{g}$ (aspect ratio is 10) $5.08 \%$ and $26.97 \%$, respectively.

It must be note that, in order to obtained reliable analyses result aspect ratio of the element must be small enough. Also, it can be occurred difference between the FEM and SPM even if aspect ratio is 1. For model a (aspect ratio is 1) $2.81 \%$ difference is obtained at fixed support moment.

In the Figure 6, the middle and side moment values for FEM models are given. As seen in the figure, difference between middle and side moment values increase by high aspect ratio of the element. Slightly differences are found especially for 1 and 2 aspect ratios. These results are confirmed from the previously obtained results.

Table 2. The difference between FEM and SPM for different aspect ratio

\begin{tabular}{|c|c|c|c|c|c|c|}
\hline \multirow{2}{*}{ Model } & \multicolumn{3}{|c|}{ Moment value at fixed support point $(\mathrm{kNm} / \mathrm{m})$} & \multicolumn{3}{|c|}{ Maximum longitudinal moment value $(\mathrm{kNm} / \mathrm{m})$} \\
\hline & FEM & SPM & Difference $(\%)$ & FEM & SPM & Difference $(\%)$ \\
\hline a & 32.150 & \multirow{7}{*}{33.081} & 2.81 & -7.602 & \multirow{7}{*}{-7.659} & 0.74 \\
\hline $\mathrm{b}$ & 31.585 & & 4.52 & -7.660 & & 0.01 \\
\hline c & 30.659 & & 7.32 & -7.804 & & 1.89 \\
\hline $\mathrm{d}$ & 29.397 & & 11.14 & -7.878 & & 2.86 \\
\hline e & 27.827 & & 15.88 & -8.048 & & 5.08 \\
\hline f & 21.540 & & 34.89 & -9.178 & & 19.83 \\
\hline g & 16.290 & & 50.76 & -9.725 & & 26.97 \\
\hline
\end{tabular}



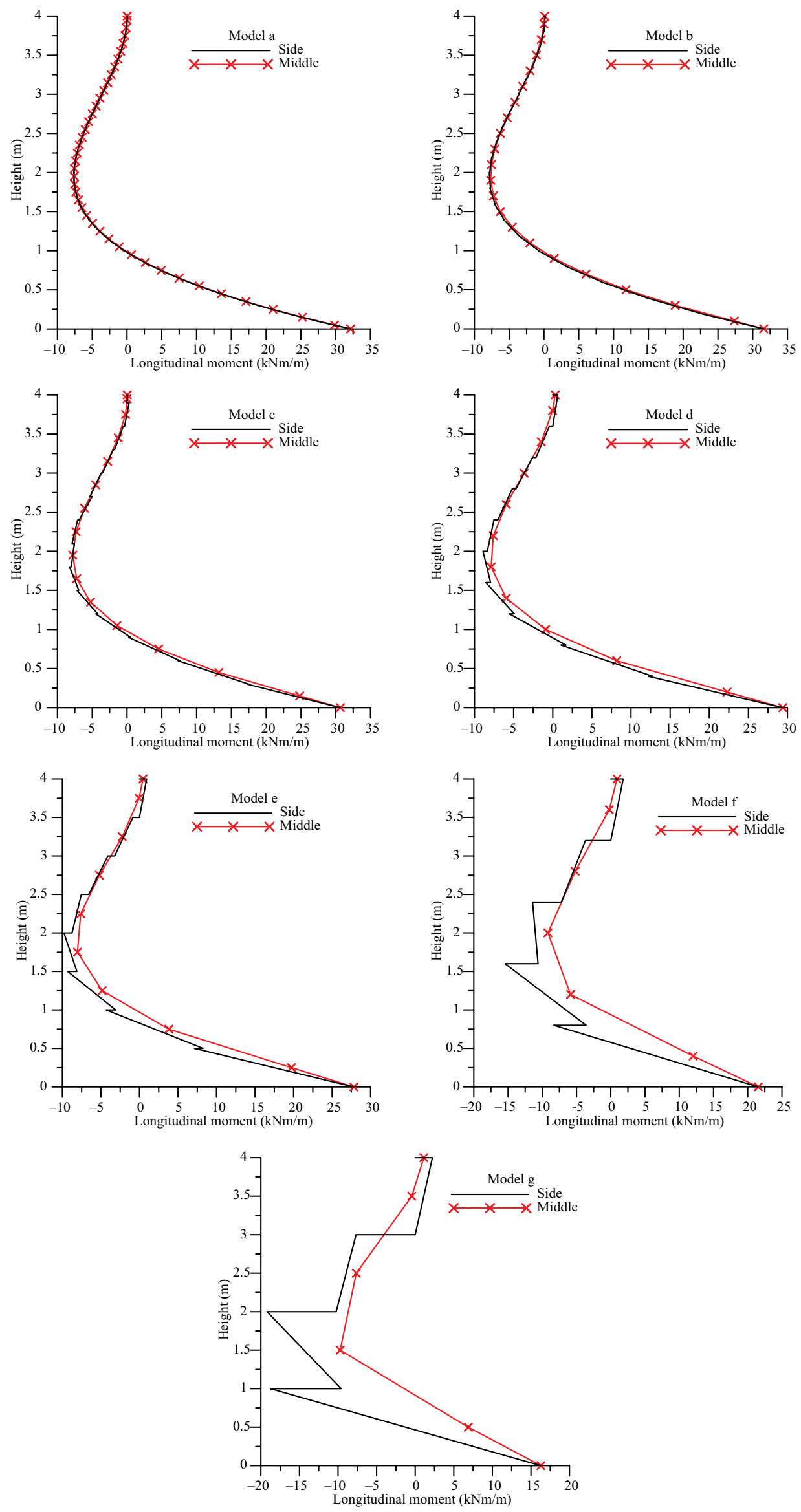

Fig. 6. FEM models longitudinal moments of middle and side of the element 


\subsection{Example 2}

As it obtained from the previous analysis it can be occurred difference between the FEM and SPM even if aspect ratio 1 . In order to investigate the effect of element dimensions on the analyses result, it is prepared three FEM models which have different dimensions but same aspect ratios. These models can be seen in Figure 7. The radius, thickness, height, elasticity modulus and Poisson's ratio of the first model is $18.25 \mathrm{~m}$, $0.50 \mathrm{~m}, 4.0 \mathrm{~m}, 2060100 \mathrm{kN} / \mathrm{m}^{2}$ and 0.15 , respectively. It is selected liquid load up to height of wall with specific weigh is $9.81 \mathrm{kN} / \mathrm{m}^{3}$, as loading.

In the models, thickness and height of the shell member is defined equal. The member dimensions and aspect ratios, which are used in the models, can be seen in the Table 3. a)

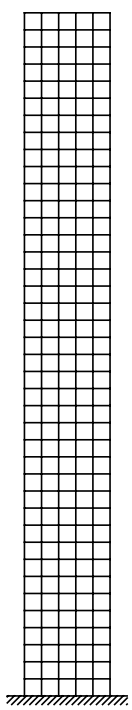

b)

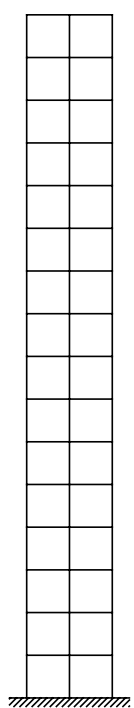

c)

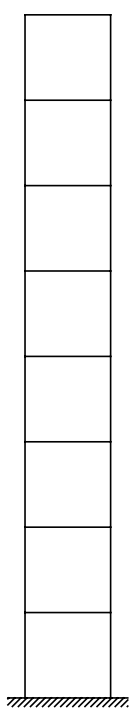

Fig. 7. FEM models of Ex.2

Table 3. Member dimensions and aspect ratios

\begin{tabular}{|c|c|c|}
\hline Model & $\begin{array}{c}\text { Finite element member } \\
\text { height/thickness }(\mathrm{m} / \mathrm{m})\end{array}$ & Aspect Ratio \\
\hline $\mathrm{a}$ & $0.10 / 0.10$ & 1 \\
\hline $\mathrm{b}$ & $0.25 / 0.25$ & 1 \\
\hline $\mathrm{c}$ & $0.50 / 0.50$ & 1 \\
\hline
\end{tabular}

In the Figure 8, FEM models analysis results can be seen. For comparing these results, SPM moment values are given on the same figure. Although all models have the same aspect ratio, the longitudinal moment differences between SPM and FEM is increasing when increasing the height (or thickness) of the elements is increasing.

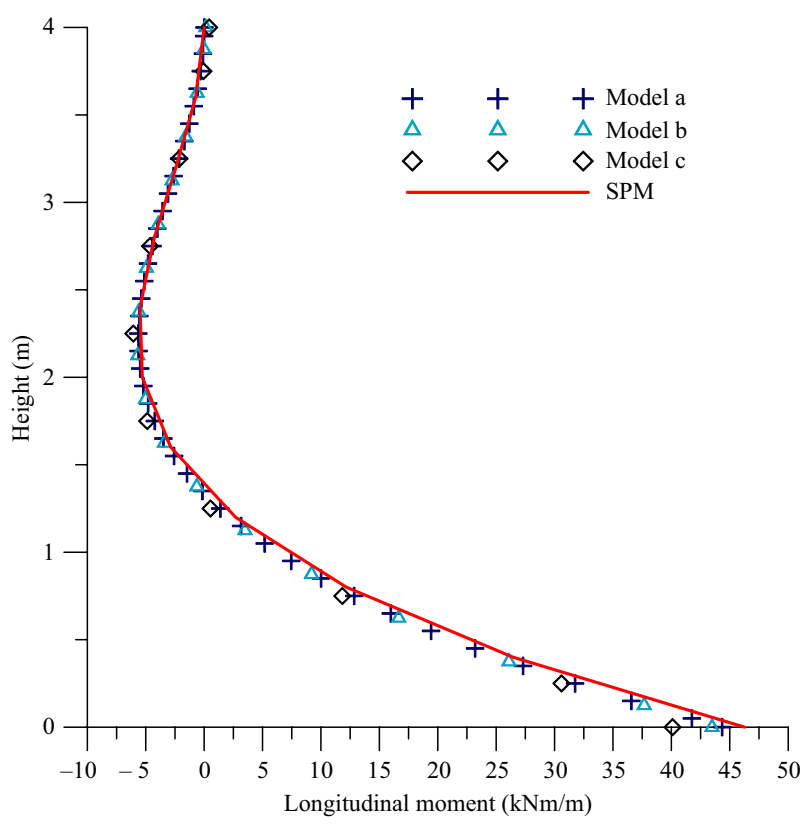

Fig. 8. Longitudinal moments for FEM models and SPM (Ex.2)

The maximum moment values obtained from analyses FEM models and SPM are given in the Table 4. As it seen in table, significant differences are found especially for model c. At longitudinal and fixed support moments, these differences are $13.36 \%$ and $10.35 \%$, respectively.

For the model a, longitudinal and fixed support moments differences are obtained $4.17 \%$ and $2.53 \%$, respectively. To decrease these differences, FEM model must be prepared properly according to the desired accuracy in the results. Although FEM is a powerful numerical analyses technique, it must note that, some differences can be occurred in the FEM analyses results.

Table 4. The difference between FEM and SPM for same aspect ratio

\begin{tabular}{|c|c|c|c|c|c|c|}
\hline \multirow{2}{*}{ Model } & \multicolumn{3}{|c|}{ Moment value at fixed support point $(\mathrm{kNm} / \mathrm{m})$} & \multicolumn{3}{|c|}{ Maximum longitudinal moment value $(\mathrm{kNm} / \mathrm{m})$} \\
\hline & FEM & SPM & Difference (\%) & FEM & SPM & Difference $(\%)$ \\
\hline a & 44.348 & \multirow{3}{*}{46.28} & 4.17 & -5.635 & \multirow{3}{*}{-5.496} & 2.53 \\
\hline $\mathrm{b}$ & 43.438 & & 6.14 & -5.683 & & 3.40 \\
\hline c & 40.099 & & 13.36 & -6.065 & & 10.35 \\
\hline
\end{tabular}




\section{Conclusions}

In this study, it is investigated, the aspect ratio factor for FEM analysis of axially symmetric cylindrical shell wall. In the first example, it is prepared 7 FEM models, aspect ratios changes 1 to 10 . According to analysis results, at the fixed support moment differences are obtained between $2.81 \%$ (aspect ratio is 1) and $50.76 \%$ (aspect ratio is 10). Also, when the aspect ratio was 4 , the difference is found $11.14 \%$. For the longitudinal moment these differences are occurred between $0.74 \%$ and $26.97 \%$. This difference basically arises from calculating moment at middle and distributing to the sides of the each shell element. To show the difference between middle and side moments values, which is obtained for different aspect ratios, these values are drawn on the same graph.

In the second example, it is aimed to show the effect of element dimensions on the analysis. It is prepared three FEM models, which has same aspect ratio but different shell element dimensions, and compared the results. In the analysis of model $0.5 \mathrm{~m}$ dimension, differences are occurred $13.36 \%$ at longitudinal and $10.35 \%$ at fixed support moments. For the model with $0.1 \mathrm{~m}$ dimension these differences are found $4.17 \%$ and $2.53 \%$, respectively.

Analysis results showed that, the assumptions and boundaries of FEM can significantly affect the analysis results, when it is not used properly. In spite of obeying the rules, it is occurred some difference in the FEM analysis results. To overcome these problems it can be employed an exact solution method.

\section{References}

Aghajari, S.; Showkati, H.; Abedi, K. 2011. Experimental investigation on the buckling of thin cylindrical shells with twostepwise variable thickness under external pressure, Structural Engineering and Mechanics 39(6): 849-860.

http://dx.doi.org/10.12989/sem.2011.39.6.849

Ansary, A. M.; Damatty, A. A.; Nassef, O. 2011. A coupled finite element genetic algorithm for 371 optimum design of stiffened liquid-filled steel conical tanks, Thin-Walled Structures 49: 482-493. http://dx.doi.org/10.1016/j.tws.2010.12.006

Barakat, S. A.; Altoubat, S. 2009. Application of evolutionary global optimization techniques in 376 the design of RC water tanks, Engineering Structures 31(2): 332-344. http://dx.doi.org/10.1016/j.engstruct.2008.09.006

Beaufait, F. W. 1977. Numerical analysis of beams on elastic foundation, Journal of Engineering Mechanics Divisions, Proceedings ASCE 103: 205-209.

Bekdaş, G. 2011. Eksenel Simetrik Kısa Silindirik Duvarların Analizi: PhD Thesis. Istanbul University.
Billington, D. P. 1965. Thin shell structures. New York: McGrawHill.

Calladine, C. R. 1983. Theory of shell structures. New York: Cambridge University Press. http://dx.doi.org/10.1017/CBO9780511624278

Cross, H. 1930. Analysis of continuous frames by distributing fixed-end moments, in Proceedings of ASCE, 9-11 July 1930, Cleveland, Ohio, 57: 919-928.

Eisenberger, M.; Yankelevsky, D. Z. 1984. Exact stiffness matrix for beams on elastic foundation, Computers and Structures 21(6): 1355-1359.

http://dx.doi.org/10.1016/0045-7949(85)90189-0

Eisenberger, M.; Yankelevsky, D. Z. 1986. Analysis of beam column on elastic foundation, Computers and Structures 23(3): 351-356. http://dx.doi.org/10.1016/0045-7949(86)90226-9

Ghali, A. 1979. Circular storage tanks and soils. London: Spon Ltd.

Hetenyi, M. 1936. Analysis of bars on elastic foundation. Final Report of the Second International Congress for Bridge and Structural Engineering. Berlin-Munich:Verlag von Wilhelm Ernst and Son, 846-851.

Hetenyi, M. 1946. Beams on elastic foundation. Ann Arbor: The University of Michigan Press.

Iyengar, K. T. S. R.; Anantharamu, S. 1963. Finite beam-columns on elastic foundations, Journal of Engineering Mechanics Divisions, Proceedings ASCE 89: 139-160.

Iyengar, K. T. S. R.; Anantharamu, S. 1965. Influence lines for beams on elastic foundations, Journal of the Structural Division, Proceedings ASCE 91(3): 45-56.

Jones, G. 1997. Analysis of beams on elastic foundations using finite difference theory. New York: Thomas Telford Ltd.

Kala, Z. 2007. Stability problems of steel structures in the presence of stochastic and fuzzy uncertainty, Thin-Walled Structures 45: 861-865.

http://dx.doi.org/10.1016/j.tws.2007.08.007

Karaşin, H. A.; Gülkan, P. 2008. Elastik Zeminlere Oturan Plakların Sonlu Izgara Yöntemi ile Yaklaşık Çözümü, IMO Teknik Dergi. Paper No. 293: 4445-4454.

Kelkar, V. S.; Sewell, R. T. 1987. Fundamentals of the analysis and design of shell structures. Englewood Cliffs, NJ: PrenticeHall.

Kerr, A. D. 1976. On the stress analysis of rails and ties, in Proceedings of American Railway Engineering Association 78: 19-45.

Lakshmia, K.; Rao, A. R. M. 2012. Multi-objective optimal design of laminate composite shells and stiffened shells, Structural Engineering and Mechanics 43(6): 771-794. http://dx.doi.org/10.12989/sem.2012.43.6.771

Levinton, Z. 1947. Elastic foundation analyzed by the method of redundant reactions, Journal of the Structural Division, Proceedings ASCE 73: 1529-1541.

Melerski, E. D. 2000. Design analysis of beams, circular plates and cylindrical tanks on elastic foundations. London: Taylor \& Francis Group.

Miranda, C.; Nair, K. 1966. Finite beams on elastic foundation, Journal of the Structural Division, Proceedings ASCE 92: 131-142. 
Öztorun, N. K.; Altın, S.; Anıl, Ö. 1996. Eksenel Simetrik Silindirik Duvarların Beş Moment Denklemi ile Analizi, Journal of Faculty Engineering and Architecture of Gazi University 11: 55-72.

Öztorun, N. K.; Utku, M. 2002. Computer aided design of posttensioned concrete reservoirs, Computers and Structures 80: 2195-2207.

http://dx.doi.org/10.1016/S0045-7949(02)00244-4

Penzien, J. 1960. Discontinuity stresses in beams on elastic foundation, Journal of the Structural Division, Proceedings ASCE 86: 67-97.

Popov, E. P. 1951. Successive approximations for beams on an elastic foundation, Transactions of ASCE 116(1): 1083-1095.

Selvadurai, A. P. S. 1979. Elastic analysis of soil-foundation interaction. Amsterdam: Elsevier Scientific Publishing Company.

Shariati, M.; Hatami, H.; Torabi, H.; Epakchi, H. R. 2012. Experimental and numerical investigations on the ratcheting characteristics of cylindrical shell under cyclic axial loading, Structural Engineering and Mechanics 44(6): 753-762. http://dx.doi.org/10.12989/sem.2012.44.6.753

Timoshenko, S. P.; Woinowsky-Krieger, S. 1984. Theory of plates and shells. $2^{\text {nd }}$ ed. New York: McGraw-Hill.

Ting, B. Y. 1982. Finite beams on elastic foundation with restraints, Journal of the Structural Division, Proceedings ASCE 108: 611-621.
Umansky, A. A. 1933. Analysis of beams on elastic foundation. Central Research Institute of Auto-Transportation, Leningrad.

Ventsel, E.; Krauthammer, T. 2001. Thin plates and shells: theory, analysis and applications. New York: Marcel Dekker Inc. http://dx.doi.org/10.1201/9780203908723

Wang, Y. H.; Tham, L. G.; Cheung, Y. K. 2005. Beams and plates on elastic foundation: a review, Progress in Structural Engineering and Materials 7(4): 174-182.

http://dx.doi.org/10.1002/pse.202

Winkler, E. 1867. Die Lehre von der Elasticitaet und Festigkeit mit Besonderer Rücksicht auf ihre Anwendung in der Technik, für Polytechnische Schulen, Bauakademien, Ingenieure, Maschinenbauer, Architekten, etc. Prag: Verlag H. Dominicus.

Yas, M. H.; Aragh, B. S.; Heshmati, M. 2011. Three-dimensional free vibration analysis of functionally graded fiber reinforced cylindrical panels using differential quadrature method, Structural Engineering and Mechanics 37(5): 529-542. http://dx.doi.org/10.12989/sem.2011.37.5.529

Yu, J.; Ma, Z. 2012. Guided viscoelastic wave in circumferential direction of orthotropic cylindrical curved plates, Structural Engineering and Mechanics 41(5): 605-615. http://dx.doi.org/10.12989/sem.2012.41.5.605

Gebrail BEKDAŞ, PhD, is researcher in Numerical Analysis and Optimization at Istanbul University. He obtained his DPhil in Structural Engineering from Istanbul University with a thesis subject of design of cylindrical walls. He co-organized 15th EU-ME Workshop: Metaheuristic and Engineering in Istanbul. About optimization, he organized several mini-symposiums or special sections in prestigious international events such as 11th World Congress on Computational Mechanics (WCCM2014), International Conference on Engineering and Applied Sciences Optimization (OPTI 2014), 11 th Biennial International Conference on Vibration Problems (ICOVP2013), 3rd European Conference of Civil Engineering and 10th - 11th International Conference of Numerical Analysis and Applied Mathematics (ICNAAM). He has authored nearly 70 papers for journals and scientific events.

Namık Kemal ÖZTORUN, graduated from Civil Engineering in 1981 at Middle East Technical University. He got his master degree from Structural Engineering in 1983 from the same university. He worked on the Dynamic Analysis of Dam-Reservoir Interaction Systems for his master thesis topic. He obtained his DPhil in Structural Engineering from Middle East Technical University with a thesis subject of computer analysis of multi-storey building structures. He developed several journal and conference papers about structural mechanic, numerical analysis of structures, retrofit of structures, etc. He is at Istanbul University as a professor since 1998 . 